\title{
Mycobacterium avium Subspecies paratuberculosis and Bovine Leukemia Virus Seroprevalence and Associated Risk Factors in Commercial Dairy and Beef Cattle in Northern and Northeastern China
}

\author{
Wu-Wen Sun, ${ }^{1}$ Wen-Fa Lv, ${ }^{1}$ Wei Cong, ${ }^{1}$ Qing-Feng Meng, ${ }^{2}$ \\ Chun-Feng Wang, ${ }^{1}$ Xiao-Feng Shan, ${ }^{1}$ and Ai-Dong Qian ${ }^{1}$ \\ ${ }^{1}$ College of Animal Science and Technology, Jilin Agriculture University, Changchun, Jilin 130118, China \\ ${ }^{2}$ Jilin Entry-Exit Inspection and Quarantine Bureau, Changchun, Jilin 130000, China \\ Correspondence should be addressed to Wei Cong; messicw@163.com and Ai-Dong Qian; qianaidong0115@163.com
}

Received 30 June 2015; Revised 8 September 2015; Accepted 20 September 2015

Academic Editor: Leon Spicer

Copyright (C) $2015 \mathrm{Wu}$-Wen Sun et al. This is an open access article distributed under the Creative Commons Attribution License, which permits unrestricted use, distribution, and reproduction in any medium, provided the original work is properly cited.

\begin{abstract}
Mycobacterium avium subspecies paratuberculosis (MAP) and bovine leukemia virus (BLV) are important pathogens, commonly responsible for economical loss to cattle farms all over the world, yet their epidemiology in commercial dairy and beef cattle in China is still unknown. Thus, from September 2013 to December 2014, a large-scale seroprevalence study was conducted to determine the seroprevalence and identify herd-level risk factors associated with MAP and BLV infection. The source sample was 3674 cattle from 113 herds in northern and northeastern China. Antibodies against MAP and BLV were detected using ELISA tests. At animal-level, the seroprevalence of antibodies against MAP and BLV was 11.79\% (433/3674) and 18.29\% (672/3674), respectively. At herd-level, the seroprevalence of antibodies against MAP and BLV was 20.35\% and 21.24\% (24/113), respectively. Herd size was identified to be associated with MAP infection while herd size and presence of cattle introduced from other farms were significantly associated with BLV infection. Further research is needed to confirm these findings and improve the knowledge of the epidemiology of these two pathogens in these regions and elsewhere in China.
\end{abstract}

\section{Introduction}

Paratuberculosis, also known as Johne's disease caused by Mycobacterium avium subsp. paratuberculosis (MAP), is a chronic infectious granulomatous enteritis of global importance in primarily domestic and wild ruminants $[1,2]$. This infection can induce significant economic losses in cattle due to reduced milk production and premature culling [3], decreased value at slaughter [4], and eventual death [5]. Other economic losses can also be caused by the presence of paratuberculosis in cattle herds including reduced feed efficiency, decreased milk's fat and protein content, decreased fertility, and increased incidence of mastitis [6].

Bovine leukemia virus (BLV), an exogenous C-type oncovirus retrovirus, is the causative pathogen of enzootic bovine leucosis (EBL), lymphomas in bovine species [7].
Most of infected cattle do not develop clinical symptoms. However, nearly one-third of BLV carriers develop a form of the disease known as persistent lymphocytosis (PL), and malignant B-cell lymphosarcomas can only be found in 1$5 \%$ of BLV-infected animals [7]. BLV infection has a global distribution, and EBL is an important group of commonly major diseases that have huge implications in economic losses around the world and cause a sanitary barrier to international trade [8]. In some countries, EBL has been successfully uprooted via national control and elimination programs, such as those used in Europe $[9,10]$.

To date, very limited information on the seroprevalence of MAP and BLV infections in cattle is available in China. In order to address this lack of publication issue, the objective of this study was to describe the seroprevalence of MAP and BLV infections in commercial dairy and beef cattle in 


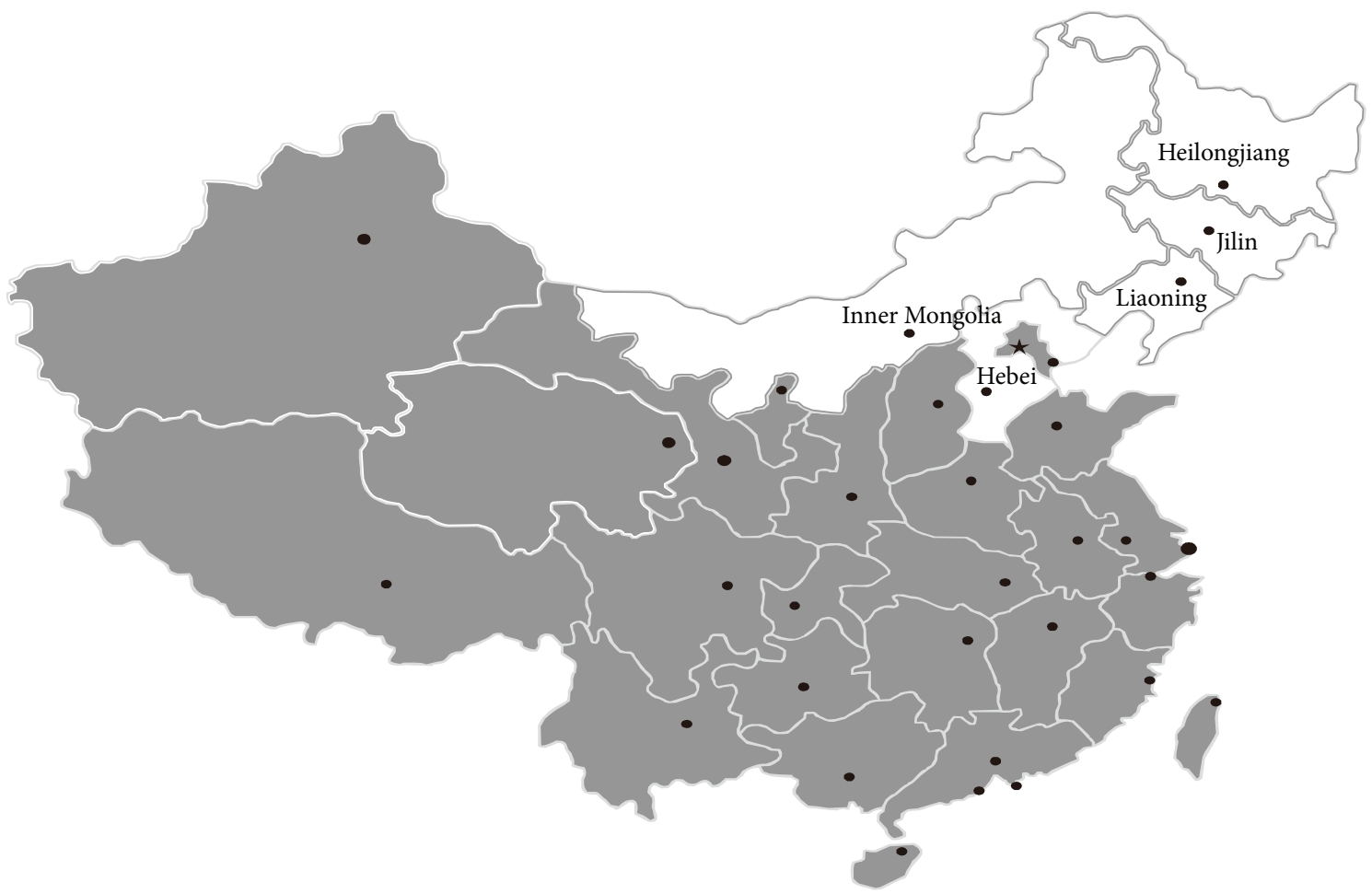

FIGURE 1: Geographic distribution of cattle sampled regions in China.

northern and northeastern China and clarify risk factors associated with seroprevalence of MAP and BLV in the study regions.

\section{Materials and Method}

2.1. Ethics Statement. This study was approved by the Animal Ethics Committee of Jilin Agriculture University, China. Cattle of various categories (dairy cattle and beef cattle), from which serum samples were collected, were handled with good ethical animal practices required by the Animal Ethics Procedures and Guidelines of the People's Republic of China. The collection of serum samples was performed as part of routine process of disease monitoring and surveillance program for these cattle. The owners of cattle had given permission for collecting the serum samples.

2.2. Serum Samples. A total of 3674 bovine blood samples were collected from four provinces (Heilongjiang, Jilin, Liaoning, Hebei, and Inner Mongolia Autonomous Region) (Figure 1) between September 2013 and December 2014. Blood samples were collected from 12 administrative districts and 113 herds with 50 cattle and more across the five regions. Cattle sample sources from each farm were selected randomly using a table of random digits. Several large-scale farms (with more than 150 livestock animals) were not included because the owner was often not present to give permission. In the case of cattle, approximately $10 \%$ in each farm were sampled. All of the animals sampled were clinically healthy. Blood samples $(10 \mathrm{~mL})$ of each animal were collected by puncturing the tail vessel using sterile tubes sans/without anticoagulant. Samples were kept at $4^{\circ} \mathrm{C}$ and centrifuged at $1000 \times \mathrm{g}$ for $15 \mathrm{~min}$. The serum was separated and stored at $-20^{\circ} \mathrm{C}$ until analysis.

2.3. Serological Examination. The serological examination of MAP was performed by the commercial antibody detection kits (Pourquier-IDEXX ELISA Paratuberculosis Screening and Verification Ab Test) following the recommended protocol. The antibodies to BLV were detected using a commercially available verification ELISA kit (Pourquier, Montpellier, France) following the manufacturer's instructions.

2.4. Epidemiological Data Collection. Data obtained with the epidemiological questionnaires were used in the analysis of risk factors associated with the animal-level and herd-level target prevalence. For animal-level variables, information about species, geographic origin (Heilongjiang/Jilin/Liaoning/Hebei/Inner Mongolia Autonomous Region), age, gender, and abortion history was acquired from farm administrators. For herd-level variables, the respective categories were as follows: region (Heilongjiang/Jilin/Liaoning/Hebei/Inner Mongolia Autonomous Region), herd size (small (50$100)$ /medium (100-150)/large (>150)), mixed farming (yes: dairy and beef cattle/no: dairy cattle only or beef cattle only), methods of cattle house cleaning (not practiced/sweeping/ water hosing), source of water (well/tap water), management system (intensive: very strict control for irrelevant personnel and animals/semi-intensive: slight control for irrelevant personnel and animals/extensive: no control for irrelevant 
TABLE 1: Bivariate analysis for the animal-level seropositivity of Mycobacterium avium subspecies paratuberculosis (MAP) and bovine leukemia virus (BLV) infection in commercial dairy and beef cattle in northern and northeastern China.

\begin{tabular}{|c|c|c|c|c|c|c|c|}
\hline \multirow{2}{*}{ Characteristics } & \multirow{2}{*}{$\begin{array}{c}\text { Cattle tested } \\
\text { (number) }\end{array}$} & \multicolumn{3}{|l|}{ MAP } & \multicolumn{3}{|l|}{ BLV } \\
\hline & & Number of positive cattle & $\%$ & $P$ value & Number of positive cattle & $\%$ & $P$ value \\
\hline \multicolumn{8}{|l|}{ Species } \\
\hline Dairy cattle & 2044 & 251 & 12.28 & \multirow{2}{*}{0.317} & 378 & 18.49 & \multirow{2}{*}{0.722} \\
\hline Beef cattle & 1630 & 182 & 11.17 & & 294 & 18.04 & \\
\hline \multicolumn{8}{|l|}{ Region } \\
\hline Heilongjiang & 594 & 72 & 12.12 & \multirow{5}{*}{0.150} & 103 & 17.34 & \multirow{5}{*}{0.126} \\
\hline Jilin & 638 & 86 & 13.48 & & 134 & 21.00 & \\
\hline Liaoning & 673 & 95 & 14.12 & & 131 & 19.47 & \\
\hline Hebei & 712 & 73 & 10.25 & & 145 & 20.37 & \\
\hline Inner Mongolia Autonomous Region & 957 & 107 & 11.18 & & 159 & 16.61 & \\
\hline \multicolumn{8}{|l|}{ Age } \\
\hline$\leq 1$ year & 995 & 98 & 9.85 & \multirow{4}{*}{$<0.001$} & 128 & 12.86 & \multirow{4}{*}{$<0.001$} \\
\hline 2-3 year & 1278 & 103 & 8.06 & & 226 & 17.68 & \\
\hline 4-5 year & 689 & 101 & 14.66 & & 142 & 20.61 & \\
\hline$\geq 6$ year & 712 & 131 & 18.40 & & 176 & 24.72 & \\
\hline \multicolumn{8}{|l|}{ Gender } \\
\hline Male & 1277 & 164 & 12.84 & \multirow{2}{*}{0.147} & 214 & 16.76 & \multirow{2}{*}{0.079} \\
\hline Female & 2397 & 269 & 11.22 & & 458 & 19.11 & \\
\hline \multicolumn{8}{|l|}{ Abortion history } \\
\hline No & 3162 & 327 & 10.34 & \multirow{3}{*}{$<0.001^{*}$} & 556 & 17.58 & \multirow{3}{*}{0.006} \\
\hline Yes & 512 & 106 & 20.70 & & 116 & 22.65 & \\
\hline Total & 3674 & 433 & 11.79 & & 672 & 18.29 & \\
\hline
\end{tabular}

personnel and animals), presence of cattle introduced from other farms (yes/no), presence of other animals (yes/no), type of production (beef/milk/mixed), and veterinary service (yes/no).

2.5. Statistical Analysis. In this study, an infected farm was defined as a farm with one or more infected animals. Explanatory variables thought to influence the MAP and BLV seroprevalence were in two broad categories: animallevel variables and herd-level variables. Explanatory variables were tested for their relationship with the MAP and BLV seroprevalence by the Mantel-Haenszel Chi-square test and bivariate analyses. Variables were included in the multivariate analysis if they had a $P$ value of equal to or less than 0.20 in the bivariate analysis. Region was used as a concomitant variable in the multivariate analysis. Adjusted odds ratio (OR) and its 95\% confidence interval were calculated by multivariate logistic regression analysis. A $P$ value less than 0.05 was considered statistically significant. Results were analyzed with SPSS 19.0 software package.

\section{Results}

3.1. Seroprevalence and Risk Factor Analysis of MAP. At animal-level, of the 3674 samples tested, positive results for anti-MAP antibodies were observed in 433 samples, representing a prevalence of $11.79 \%$ (95\% confidence interval (CI): 15.65-19.64). The results of bivariate analyses are shown in Table 1. Of these, the seroprevalence of MAP was diverse in different regions; the most frequent level was $14.12 \%$ (95/673) in Liaoning province, followed by $13.48 \%(86 / 638)$ in Jilin province, $12.12 \%$ (72/594) in Heilongjiang province, $11.18 \%$ (107/957) in Inner Mongolia Autonomous Region, and 10.25\% (73/712) in Hebei province. Among different ages of cattle, the highest seroprevalence of MAP infection was seen in cattle aged $\geq 6$ years $(18.40 \%)$. With respect to gender, the seroprevalence in male cattle $(12.84 \%)$ was higher than that in female cattle (11.22\%). Moreover, cattle with abortion history $(20.70 \%)$ have a significantly higher seroprevalence than that in cattle without abortion history $(10.34 \%)(P<0.001)$.

The herd-level prevalence was 20.35\% (23/113, 95\% CI: 12.93-27.78). The results of the bivariate analysis for risk factors are presented in Table 2. The herd-level prevalence was $10.53 \%$ in Heilongjiang province, $16.67 \%$ in Jilin province, $28.57 \%$ in Liaoning province, $22.22 \%$ in Hebei province, and $22.73 \%$ in Inner Mongolia Autonomous Region. The variables selected $(P \leq 0.2)$ for the multivariate analysis were as follows: herd size, methods of cleaning, source of water, and presence of cattle introduced from other farms. Herd size was identified to be associated with MAP infection in cattle in the multivariate analysis (Table 4).

3.2. Seroprevalence and Risk Factor Analysis of BLV. Overall, at animal-level sample source, 672 out of 3674 serum samples (18.29\%, 95\% CI: 48.64-51.56) were seropositive for BLV by ELISA test. The results of bivariate analyses are shown in Table 1. Among different types of cattle, dairy cattle (18.49\%) had a little higher seroprevalence than that in beef cattle 
TABLE 2: Bivariate analysis for the herd-level seropositivity of Mycobacterium avium subspecies paratuberculosis (MAP) and bovine leukemia virus (BLV) infection in commercial dairy and beef farms in northern and northeastern China.

\begin{tabular}{|c|c|c|c|c|c|}
\hline \multirow[b]{2}{*}{ Variables } & \multirow[b]{2}{*}{ Number of the sampled } & \multicolumn{2}{|l|}{ MAP } & \multicolumn{2}{|l|}{ BLV } \\
\hline & & $\begin{array}{c}\text { Number of } \\
\text { positive cattle }(\%)\end{array}$ & $P$ & $\begin{array}{c}\text { Number of } \\
\text { positive cattle (\%) }\end{array}$ & $P$ \\
\hline \multicolumn{6}{|l|}{ Region } \\
\hline Heilongjiang & 19 & $2(10.53)$ & \multirow{5}{*}{0.673} & $4(21.05)$ & \multirow{5}{*}{0.930} \\
\hline Jilin & 24 & $4(16.67)$ & & $4(16.67)$ & \\
\hline Liaoning & 21 & $6(28.57)$ & & $5(23.81)$ & \\
\hline Hebei & 27 & $6(22.22)$ & & $7(25.93)$ & \\
\hline Inner Mongolia Autonomous Region & 22 & $5(22.73)$ & & $4(18.18)$ & \\
\hline \multicolumn{6}{|l|}{ Herd size } \\
\hline Small $(50-100)$ & 52 & $9(17.31)$ & \multirow{3}{*}{0.024} & $8(15.38)$ & \multirow{3}{*}{0.002} \\
\hline Medium (100-150) & 46 & $7(15.22)$ & & $6(13.04)$ & \\
\hline Large $(>150)$ & 15 & $7(46.67)$ & & $8(53.33)$ & \\
\hline \multicolumn{6}{|l|}{ Mixed farming } \\
\hline Yes & 33 & $7(21.21)$ & \multirow{2}{*}{0.884} & $8(24.24)$ & \multirow{2}{*}{0.616} \\
\hline No & 80 & $16(20.00)$ & & $16(20.00)$ & \\
\hline \multicolumn{6}{|l|}{ Methods of cleaning } \\
\hline Not practiced & 13 & $6(46.15)$ & \multirow{3}{*}{0.038} & $7(53.85)$ & \multirow{3}{*}{0.007} \\
\hline Sweeping & 39 & $8(20.51)$ & & $8(20.51)$ & \\
\hline Water hosing & 61 & $9(14.75)$ & & $9(14.75)$ & \\
\hline \multicolumn{6}{|l|}{ Source of water } \\
\hline Well & 41 & $11(26.83)$ & \multirow{2}{*}{0.197} & $13(31.70)$ & \multirow{2}{*}{0.040} \\
\hline Tap water & 72 & $12(16.67)$ & & $11(15.28)$ & \\
\hline \multicolumn{6}{|l|}{ Management system } \\
\hline Intensive & 35 & $4(11.43)$ & \multirow{3}{*}{0.227} & $3(8.57)$ & \multirow{3}{*}{0.036} \\
\hline Semi-intensive & 46 & $10(21.74)$ & & $10(21.74)$ & \\
\hline Extensive & 32 & $9(28.13)$ & & $11(34.38)$ & \\
\hline \multicolumn{6}{|l|}{ Presence of other animals } \\
\hline No & 76 & $15(19.74)$ & \multirow{2}{*}{0.815} & $16(21.05)$ & \multirow[t]{2}{*}{0.945} \\
\hline Yes & 37 & $8(21.62)$ & & $8(21.62)$ & \\
\hline \multicolumn{6}{|c|}{ Presence of cattle introduced from other farms } \\
\hline No & 81 & $14(17.28)$ & \multirow{2}{*}{0.197} & $13(16.05)$ & 0.032 \\
\hline Yes & 32 & $9(28.13)$ & & $11(34.38)$ & 0.032 \\
\hline Type of production & & & & & \\
\hline Beef & 26 & $3(11.54)$ & & $5(19.23)$ & \\
\hline Milk & 72 & $15(20.83)$ & 0.245 & $13(18.06)$ & 0.161 \\
\hline Mixed & 15 & $5(33.33)$ & & $6(40.00)$ & \\
\hline Veterinary service & & & & & \\
\hline No & 43 & $11(25.58)$ & 0.279 & $14(32.56)$ & 0.021 \\
\hline Yes & 70 & $12(17.14)$ & 0.219 & $10(14.29)$ & 0.021 \\
\hline
\end{tabular}

(18.04\%). In terms of geographical origin, BLV seroprevalence varied in cattle from different regions, ranging from $16.61 \%$ in Inner Mongolia Autonomous Region to $21.00 \%$ in Jilin province. Positive cattle were found in all four age groups, varied from $12.86 \%$ to $24.72 \%$, and the highest seroprevalence was detected in cattle of more than 6-year-old category. Seroprevalence of BLV in male and female cattle was $16.76 \%$ (214/1277) and 19.11\% (458/2397), respectively. Cattle with abortion history (22.65\%) have significantly higher seroprevalence than that in cattle without abortion history (17.58\%) $(P=0.006)$.

The herd-level prevalence was $21.24 \%$ (24/113, 95\% CI: 13.70-28.78). The results of the bivariate risk factors analysis are presented in Table 2. The herd-level prevalence was $21.05 \%$ in Heilongjiang province; $16.67 \%$ in Jilin province; 23.81\% in Liaoning province; $25.93 \%$ in Hebei province; and 
TABLE 3: Multivariate analysis of risk factors associated with animal-level prevalence of Mycobacterium avium subspecies paratuberculosis (MAP) and bovine leukemia virus (BLV) in commercial dairy and beef cattle in northern and northeastern China.

\begin{tabular}{|c|c|c|c|c|}
\hline Agents & Variables $^{\mathrm{a}}$ & Adjusted odds ratio $^{\mathrm{b}}$ & 95\% confidence interval & $P$ value \\
\hline \multirow{8}{*}{ MAP } & Age & & & \\
\hline & $\leq 1$ year & Reference & & \\
\hline & 2-3 year & 0.792 & $0.594-1.056$ & 0.112 \\
\hline & 4-5 year & 1.503 & $1.117-2.020$ & 0.007 \\
\hline & $\geq 6$ year & 2.033 & $1.537-2.689$ & $<0.001$ \\
\hline & Abortion $\mathrm{h}$ & & & \\
\hline & No & Reference & & \\
\hline & Yes & 2.334 & $1.833-2.971$ & $<0.001$ \\
\hline \multirow{5}{*}{ BLV } & Age & & & \\
\hline & $\leq 1$ year & Reference & & \\
\hline & 2-3 year & 1.511 & $1.194-1.913$ & $<0.001$ \\
\hline & 4-5 year & 1.775 & $1.363-2.311$ & $<0.001$ \\
\hline & $\geq 6$ year & 2.337 & $1.816-3.009$ & $<0.001$ \\
\hline
\end{tabular}

${ }^{\mathrm{a}}$ The variables included were those with a $P \leq 0.20$ obtained in the bivariate analysis.

${ }^{\mathrm{b}}$ Adjusted by region and the rest of characteristics included in this table.

$18.18 \%$ in Inner Mongolia Autonomous Region. The variables selected $(P \leq 0.2)$ for the multiple analysis were as follows: herd size, methods of cleaning, source of water, management system, presence of cattle introduced from other farms, type of production, and veterinary service. Herd size and presence of cattle introduced from other farms were significantly associated with BLV infection in the studied cattle in the multivariate analysis (Table 4).

\section{Discussion}

This is the first large-scale study of MAP and BLV antibody prevalence in commercial dairy cattle and beef cattle in China. High animal-level (11.79\%; 95\% CI: 7.3-15.4) and herdlevel (20.35\%; 95\% CI: 30.2-39.1) MAP prevalence was found in northern and northeastern China, whereas high animallevel (18.29\%; 95\% CI: 7.3-15.4) and herd-level (21.24\%; 95\% CI: 30.2-39.1) BLV prevalence was also found in the same regions, indicating that the infections are widely spread in the study regions.

In the present study, animal-level MAP seroprevalence was $11.79 \%$, but animal-level prevalence might even be higher. It is important to highlight that paratuberculosis has a comparatively long latent period, and the antibody levels against MAP only can be detected at the end of the latent period by the ELISA test, results to show that this method was noneffective for detecting infected animals in the early stages of the infection [11]. Thus, the animals that are infected at a young stage (i.e., no more than one year) will still exist in the herd, shedding MAP via feces and contaminating water and food, and will only present clinical symptoms in the adult stage [12]. However, paratuberculosis is an unknown disease for most farmers in the study regions, and although the high infection rates at animal-level and herd-level prevalence were found in these regions, most farmers are not aware of the impact of the infection and the economic losses that it can cause.
The seroprevalence of MAP significantly increased with cattle age $(P<0.001)$ (Table 3$)$ and was also significantly higher in cattle herds with $>150$ cattle compared with smaller herds $(P=0.024)$. An increase in seropositivity with herd size has also been reported in England [13] and Denmark [14]. This is not surprising because MAP is infective with an environmental component and density dependent effects are to be expected.

One of the critical issues is the probable zoonotic link between MAP and Crohn's disease, although this relation is still a vexed question and is the target of continual debates in science [15]. However, MAP has been detected in fresh and pasteurized milk [16-18], and the habit of consuming fresh and pasteurized milk is widespread in family farms in the study regions. Therefore, the validation of a zoonotic link between MAP and Crohn's disease could have great consequences for the cattle industry of the study regions and China.

BLV has a worldwide distribution and prevalence varies between countries $[9,10]$. In the present study, this is the first report of BLV infection with a $18.29 \%$ seroprevalence at animal-level sample in cattle in China, which is lower than the $70 \%$ seroprevalence in Argentina [19], 41\% in USA [20], and $32.5 \%$ in Japan [8]; however, the prevalence of BLV is much higher than the values of $2.28 \%$ in dairy cattle in Turkey [21]. Several factors may contribute to such differences, such as geographical conditions, the types and size of the cattle tested, and the specificity and sensitivity of the detection methods.

Analyses of risk factors for the animal-level sample presence of BLV revealed that age was a common risk factor for dairy and beef cattle. The seroprevalence of BLV infection in older cattle was significantly higher than that in younger cattle (Table 3). This is probably due to the fact that older cattle had more chance to contact this pathogen comparing to younger cattle, thus increasing the risk of infection.

Analyses of risk factors for the herd-level presence of BLV revealed that the herd size and presence of cattle introduced 
TABLE 4: Multivariate risk factors analysis associated with herd-level prevalence of Mycobacterium avium subspecies paratuberculosis (MAP) and bovine leukemia virus (BLV) in commercial dairy and beef farms in northern and northeastern China.

\begin{tabular}{|c|c|c|c|c|}
\hline Agents & Variables $^{\mathrm{a}}$ & Adjusted odds ratio $^{\mathrm{b}}$ & 95\% confidence interval & $P$ value \\
\hline \multirow{4}{*}{ MAP } & Herd size & & & \\
\hline & Small (50-100) & Reference & & \\
\hline & Medium (100-150) & 0.858 & $0.292-2.522$ & 0.780 \\
\hline & Large $(>150)$ & 4.181 & $1.206-14.490$ & 0.019 \\
\hline \multirow{7}{*}{ BLV } & Herd size & & & \\
\hline & Small (50-100) & Reference & & \\
\hline & Medium (100-150) & 0.825 & $0.263-2.584$ & 0.741 \\
\hline & Large $(>150)$ & 6.286 & $1.777-22.240$ & 0.002 \\
\hline & Presence of cattle introduced from other farms & & & \\
\hline & No & Reference & & \\
\hline & Yes & 2.740 & $1.070-7.016$ & 0.041 \\
\hline
\end{tabular}

${ }^{\mathrm{a}}$ The variables included were those with a $P \leq 0.20$ obtained in the bivariate analysis.

${ }^{\mathrm{b}}$ Adjusted by region and the rest of characteristics included in this table.

from other farms were a common risk factor for dairy and beef farms. Prevalence has an increasing trend with increasing herd size. The reason for this phenomenon is because the population of susceptible animals is greater in large herds. In addition, the most important risk factor for the introduction of not only exotic but also endemic diseases is movement of animals [22]. In China, farm owners rarely test animals for BLV infection ahead of their introduction into their own farms. Resultant, control measures such as negative confirmation of BLV in cattle before their introduction onto a farm should be conducted to prevent BLV infection.

In conclusion, this study firstly reported seroprevalence of MAP and BLV infection in commercial dairy and beef cattle in northern and northeastern China and also identified several herd-level risk factors associated with the presence of seropositive cattle. Future research is required to compare the influence of each factor responsible for these pathogens infection at animal- and herd-level in these regions and elsewhere in China.

\section{Conflict of Interests}

The authors declare that there is no conflict of interests in this paper.

\section{Acknowledgments}

Project support was provided by the project National Natural Science Foundation of China (Grant no. 31272566). The authors thank Professor Justin David Hill for copyediting the paper.

\section{References}

[1] J. A. VanLeeuwen, J. P. Haddad, I. R. Dohoo, G. P. Keefe, A. Tiwari, and R. Tremblay, "Associations between reproductive performance and seropositivity for bovine leukemia virus, bovine viral-diarrhea virus, Mycobacterium avium subspecies paratuberculosis, and Neospora caninum in Canadian dairy cows," Preventive Veterinary Medicine, vol. 94, no. 1-2, pp. 5464, 2010.
[2] R. Garg, P. K. Patil, S. V. Singh et al., "Comparative evaluation of different test combinations for diagnosis of Mycobacterium avium subspecies paratuberculosis infecting dairy herds in India," BioMed Research International, vol. 2015, Article ID 983978, 6 pages, 2015.

[3] E. A. Raizman, J. P. Fetrow, and S. J. Wells, "Loss of income from cows shedding Mycobacterium avium subspecies paratuberculosis prior to calving compared with cows not shedding the organism on two Minnesota dairy farms," Journal of Dairy Science, vol. 92, no. 10, pp. 4929-4936, 2009.

[4] A. B. Kudahl and S. S. Nielsen, "Effect of paratuberculosis on slaughter weight and slaughter value of dairy cows," Journal of Dairy Science, vol. 92, no. 9, pp. 4340-4346, 2009.

[5] A. B. Kudahl, S. Østergaard, J. T. Sørensen, and S. S. Nielsen, "A stochastic model simulating paratuberculosis in a dairy herd," Preventive Veterinary Medicine, vol. 78, no. 2, pp. 97-117, 2007.

[6] S. S. Nielsen and N. Toft, "Effect of management practices on paratuberculosis prevalence in Danish dairy herds," Journal of Dairy Science, vol. 94, no. 4, pp. 1849-1857, 2011.

[7] R. H. R. D’Angelino, E. M. Pituco, E. M. C. Villalobos, R. Harakava, F. Gregori, and C. Del Fava, "Detection of bovine leukemia virus in brains of cattle with a neurological syndrome: pathological and molecular studies," BioMed Research International, vol. 2013, Article ID 425646, 6 pages, 2013.

[8] K. Murakami, S. Kobayashi, M. Konishi, K.-I. Kameyama, and T. Tsutsui, "Nationwide survey of bovine leukemia virus infection among dairy and beef breeding cattle in Japan from 2009-2011," The Journal of Veterinary Medical Science, vol. 75, no. 8, pp. 1123-1126, 2013.

[9] J. Acaite, V. Tamosiunas, K. Lukauskas, J. Milius, and J. Pieskus, "The eradication experience of enzootic bovine leukosis from Lithuania," Preventive Veterinary Medicine, vol. 82, no. 1-2, pp. 83-89, 2007.

[10] L. Nuotio, H. Rusanen, L. Sihvonen, and E. Neuvonen, "Eradication of enzootic bovine leukosis from Finland," Preventive Veterinary Medicine, vol. 59, no. 1-2, pp. 43-49, 2003.

[11] M. T. Collins, "Diagnosis of paratuberculosis," The Veterinary Clinics of North America. Food Animal Practice, vol. 27, no. 3, pp. 581-591, 2011.

[12] A. L. Vilar, C. S. Santos, C. L. Pimenta et al., "Herd-level prevalence and associated risk factors for Mycobacterium avium 
subsp. paratuberculosis in cattle in the State of Paraíba, Northeastern Brazil," Preventive Veterinary Medicine, vol. 121, no. 1-2, pp. 49-55, 2015.

[13] K. A. Woodbine, Y. H. Schukken, L. E. Green et al., "Seroprevalence and epidemiological characteristics of Mycobacterium avium subsp. paratuberculosis on 114 cattle farms in south west England," Preventive Veterinary Medicine, vol. 89, no. 1-2, pp. 102-109, 2009.

[14] M. B. Jakobsen, L. Alban, and S. S. Nielsen, "A cross-sectional study of paratuberculosis in 1155 Danish dairy cows," Preventive Veterinary Medicine, vol. 46, no. 1, pp. 15-27, 2000.

[15] N. Abendaño, R. A. Juste, and M. Alonso-Hearn, "Antiinflammatory and antiapoptotic responses to infection: a common denominator of human and bovine macrophages infected with Mycobacterium avium Subsp. Paratuberculosis," BioMed Research International, vol. 2013, Article ID 908348, 7 pages, 2013.

[16] W. Y. Ayele, P. Svastova, P. Roubal, M. Bartos, and I. Pavlik, "Mycobacterium avium subspecies paratuberculosis cultured from locally and commercially pasteurized cow's milk in the Czech Republic," Applied and Environmental Microbiology, vol. 71, no. 3, pp. 1210-1214, 2005.

[17] I. Slana, M. Liapi, M. Moravkova, A. Kralova, and I. Pavlik, "Mycobacterium avium subsp. paratuberculosis in cow bulk tank milk in Cyprus detected by culture and quantitative IS900 and F57 real-time PCR," Preventive Veterinary Medicine, vol. 89, no. 3-4, pp. 223-226, 2009.

[18] H. Okura, N. Toft, and S. S. Nielsen, "Occurrence of Mycobacterium avium subsp. paratuberculosis in milk at dairy cattle farms: a systematic review and meta-analysis," Veterinary Microbiology, vol. 157, no. 3-4, pp. 253-263, 2012.

[19] G. Monti, R. Schrijver, and D. Beier, "Genetic diversity and spread of Bovine leukaemia virus isolates in Argentine dairy cattle," Archives of Virology, vol. 150, no. 3, pp. 443-458, 2005.

[20] S. L. Otta, R. Johnson, and S. J. Wells, "Association between bovine-leukosis virus seroprevalence and herd-level productivity on US dairy farms," Preventive Veterinary Medicine, vol. 61, no. 4, pp. 249-262, 2003.

[21] M. Şevik, O. Avcı, and Ö. B. İnce, "An 8-year longitudinal sero-epidemiological study of bovine leukaemia virus (BLV) infection in dairy cattle in Turkey and analysis of risk factors associated with BLV seropositivity," Tropical Animal Health and Production, vol. 47, no. 4, pp. 715-720, 2015.

[22] S. Kobayashi, A. Hidano, T. Tsutsui et al., "Analysis of risk factors associated with bovine leukemia virus seropositivity within dairy and beef breeding farms in Japan: a nationwide survey," Research in Veterinary Science, vol. 96, no. 1, pp. 47-53, 2014. 


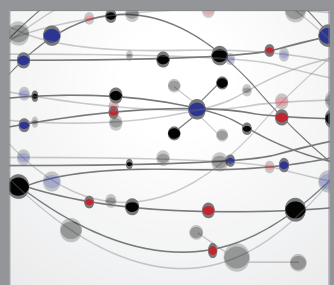

The Scientific World Journal
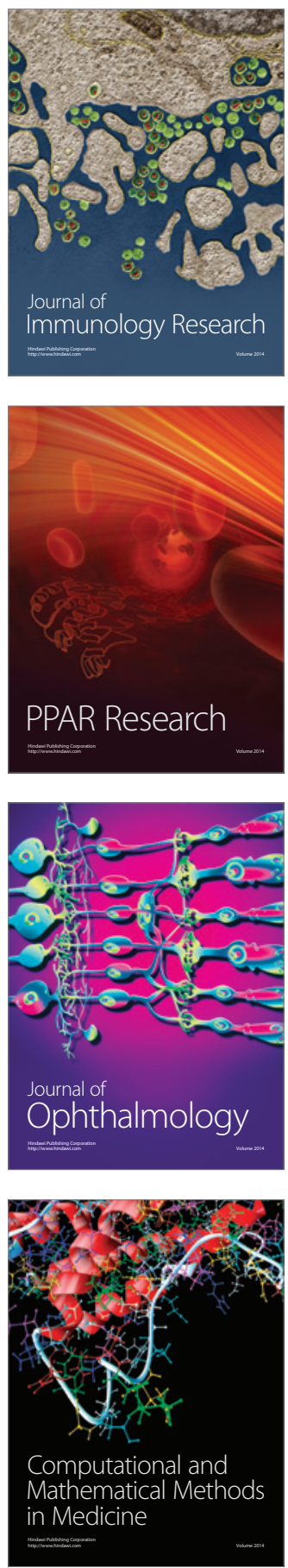

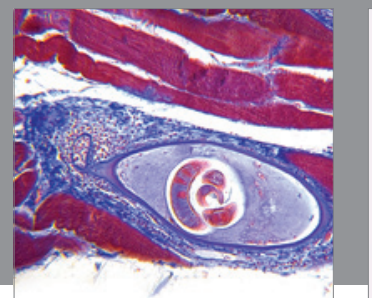

Gastroenterology

Research and Practice
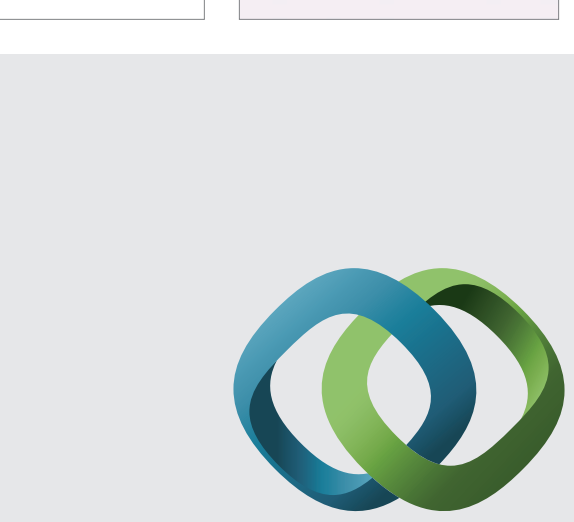

\section{Hindawi}

Submit your manuscripts at

http://www.hindawi.com
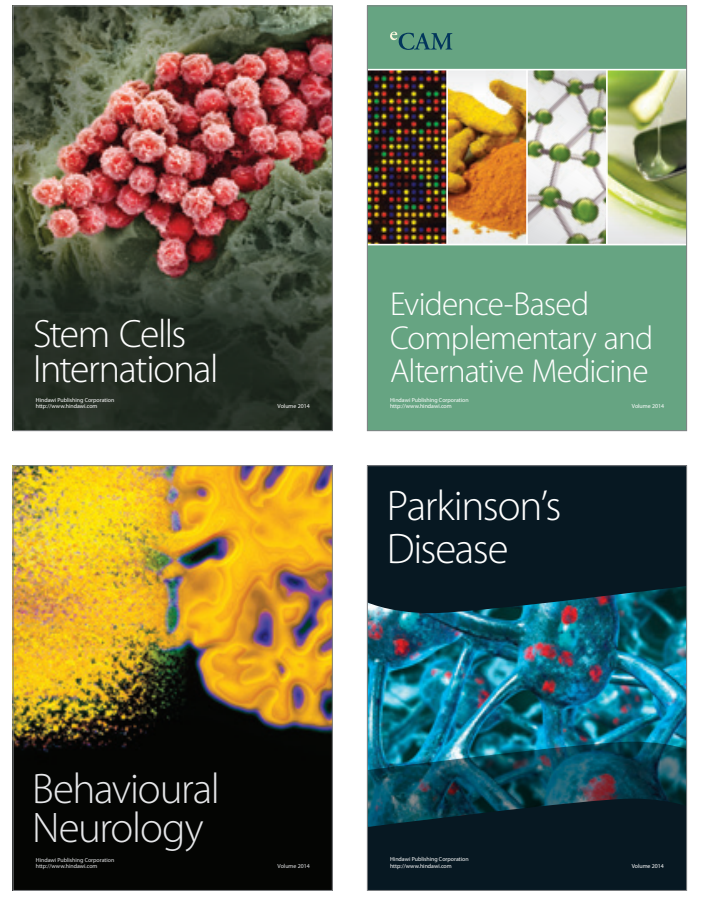
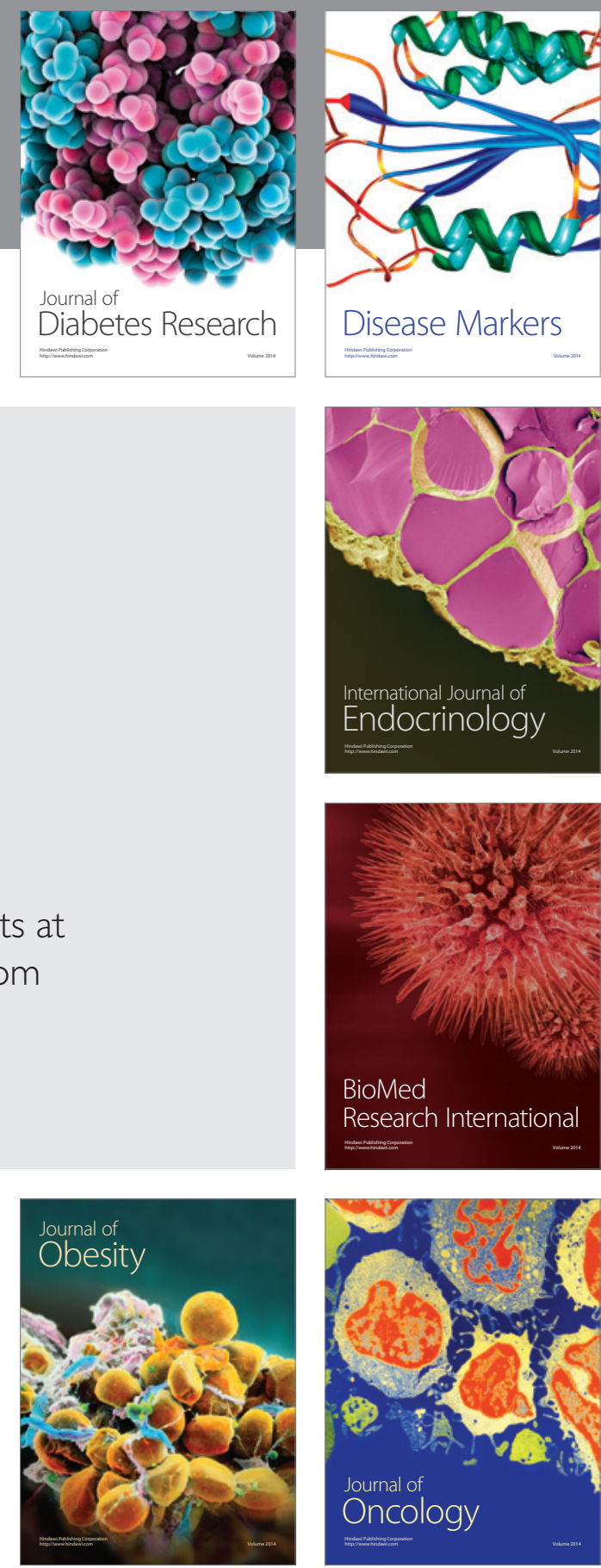

Disease Markers
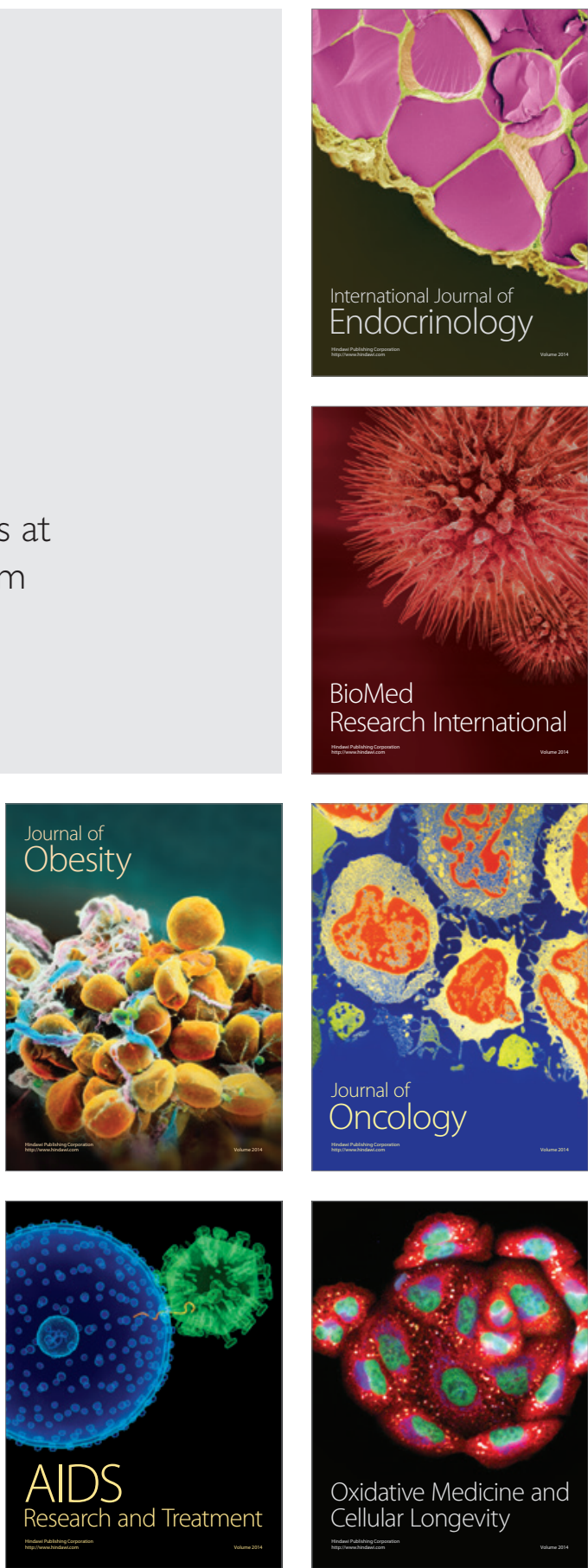